\title{
Kolorektal Kanserlerde HER-2/neu Ekspresyonunun Histopatolojik ve Prognostik Parametrelerle Korelasyonu
}

\section{Correlation of HER-2/neu Expression with Histopathological and Prognostic Parameters in Colorectal Cancers}

\author{
Serkan Yaşar ÇELIKK ${ }^{1}$, Leyla TEKIN ${ }^{1}$
}

${ }^{1}$ Muğla Sıtkı Koçman Üniversitesi Tıp Fakültesi Tıbbi Patoloji Anabilim Dalı, Muğla

\begin{abstract}
Öz
Kolorektal kanser gastrointestinal kanserlerin en s1k görülen tipidir, kadınlarda ikinci, erkeklerde üçüncü en yaygın görülen kanserdir ve kansere bağlı ölüm nedenleri arasında 3. sıradadır. Prognoz birçok klinik ve patolojik parametre ile ilişkili olsa da en önemli faktör TNM sınıflamasına göre olan evresidir. Ancak aynı patolojik evrede olmasına rağmen prognozlar arasında farklılıklar da bulunmaktadır. Bu durum TNM evresi dışında yeni prognostik ve prediktif faktörlere olan ihtiyacı ortaya koymaktadır. C-erbB2 olarak da bilinen, tirozin kinaz aktivitesi ile bir transmembran proteini kodlayan gen olan HER-2/neu, epidermal büyüme faktörü ile biyolojik olarak yakından ilişkili bir protoonkogendir. HER2/neu'nun aşırı ekspresyonu akciğer, prostat, mesane, pankreas ve meme gibi birçok epitelyal malignitelerde tespit edilmiştir. Bu çalıșmanın amacı; kolorektal kanserlerde HER2/neu onkogeni ekspresyonunu immunohistokimyasal yöntemlerle belirlemek, aşırı ekspresyonu ile çeşitli prognostik faktörler arasındaki ilişkiyi incelemektir. Çalışmamızda 20132020 tarihleri arasında hastanemizde kolorektal kanser tanısı alan 111 olguya ait rezeksiyon materyallerinden seçilen tümörlü bloklardan Leica Bond-Max cihazında, anti-C-erbB-2 antikoru(Leica) kullanılarak otomatik sistemle immunohistokimyasal boyama yapıldı. HER-2/neu'nun aşırı ekspresyonu patolojik evre, tümör diferansiasyonu, lenfovasküler invazyon, perinöral invazyon, çevre(radial) cerrahi sınır pozitifliği, lenf nodu tutulumu ve uzak metastaz varlığı ile anlamlı derecede ilişkili olduğu saptandı. Bu sonuçlar, kolorektal kanserli hastalarda HER-2/neu ekspresyonunun tespitinin, hastalığın prognozunu öngörmede ve tedavi protokollerinin belirlenmesinde yol gösterici olabileceğini düșündürmektedir.
\end{abstract} Anahtar Kelimeler: HER-2/neu, Kolorektal Kanser, Prognoz

\section{Giriş}

Kolorektal Kanser (KRK) gastrointestinal kanserlerin en sık görülen tipidir. Yaşam tarzındaki değişiklikler nedeniyle, kolorektal kanser insidansı dünya çapında giderek artmaktadır. 2018 y1lı itibariyle dünya çapında 1849518 yeni vaka olduğu tahmin edilen KRK, kadınlarda ikinci, erkeklerde üçüncü en yaygin görülen kanserdir (1). KRK, kansere bağlı ölüm nedenleri arasında üçüncü sıradadır (2). Görülme sıklığı yüksek gelir düzeyli ülkelerde en yüksek oranlarda iken, düşük ve orta

\begin{tabular}{|c|c|}
\hline \multirow{3}{*}{$\begin{array}{l}\text { Serkan Yaşar ÇELIK } \\
\text { Leyla TEKİN }\end{array}$} & ORCID No \\
\hline & 0000-0001-6557-1451 \\
\hline & 0000-0003-1172-5536 \\
\hline \multirow{2}{*}{$\begin{array}{l}\text { Başvuru Tarihi / Received: } \\
\text { Kabul Tarihi / Accepted : }\end{array}$} & 10.07 .2020 \\
\hline & 28.07.2020 \\
\hline \multirow{2}{*}{\multicolumn{2}{|c|}{$\begin{array}{l}\text { Adres / Correspondence : Serkan Yaşar ÇELIKK } \\
\text { Muğla Sıtkı Koçman Üniversitesi Tıp Fakültesi Tıbbi Patoloji } \\
\text { Anabilim Dalı, Muğla }\end{array}$}} \\
\hline & \\
\hline e-posta / e-mail : & sycelik@gmail.com \\
\hline
\end{tabular}

\begin{abstract}
Colorectal cancer is the most common type of gastrointestinal cancers. It is the second most common cancer in women and the third in men and it is the third leading cause of cancer-related death. Although prognosis is associated with many clinical and pathological parameters, the most important factor is TNM stage. However, despite the same pathological stage, there are also differences between prognoses in different patients. This situation reveals the need for new prognostic and predictive factors except the TNM stage. HER-2/neu, also known as C-erbB-2, is a gene that encodes a transmembrane protein with tyrosine kinase activity and closely related to the epidermal growth factor. Overexpression of HER-2/neu has been detected in many epithelial malignancies such as lung, prostate, bladder, pancreas and breast. The aim of this study is to determine the expression of HER-2/neu oncogene in colorectal cancers by immunohistochemical methods, to evaluate the relationship between overexpression and various prognostic factors. In our study, we selected resection materials of 111 patients diagnosed as colorectal cancer in our hospital between 2013 and 2020, and performed immunohistochemical staining automatically with anti-C-erbB-2 antibody (Leica) in Leica Bond-Max device. Overexpression of HER-2/neu was found to be significantly associated with pathological stage, tumor differantion, lymphovascular invasion, perineural invasion, radial surgical margin positivity, lymph node involvement and presence of distant metastases. These results suggest that the detection of HER-2/neu expression in patients with colorectal cancer may be helpful in predicting the prognosis of the disease and determining the treatment protocols.
\end{abstract}

Keywords: Colorectal Cancer, HER-2/neu, Prognosis

gelir düzeyli ülkelerde de KRK insidansı hızla artmaktadır. Avustralya, Kanada ve ABD'de genç yetişkinlerde insidans artış eğilimleri bildirilmiştir (1).

KRK gelişiminde ve progresyonunda gen mutasyonları, onkogenleri içeren genetik faktörler, çevresel faktörler gibi multifaktörler etkili olmaktadır. Prognoz; yaş, cinsiyet, tümör yerleşim yeri, tümör boyutu, tümörün tek veya çok odaklı oluşu, makroskopik tipi, tıkanıklık ve perforasyona yol açıp açmaması, mikroskopik tümör tipi, mikroskopik tümör derecesi, invazyon derinliği, vasküler ve perinöral invazyon olup olmamas1, peritümöral lenfositik infiltrasyon, lenf nodu tutulumu, tümör evresi gibi birçok klinik ve patolojik parametre ile ilişkili olsa da en önemli faktör TNM sınıflamasına göre olan evresidir. Ancak aynı patolojik evrede olmasına rağmen hastaların prognozları arasında farklılıklar da bulunmaktadır. Bu durum TNM evresi dişında yeni prognostik ve prediktif faktörlere olan ihtiyac1 ortaya koymaktadır (3). 
Son zamanlarda monoklonal antikorların ortaya çıkışı ve bu konudaki gelişmelerle tedavi rejimlerinde ilerlemeler kaydedilmektedir. Bu durum prognostik belirteç ve tedavide hedef ajan arayışı açısından moleküler ve biyolojik ajanlara yönelik araştırmalara ağırlık verilmesine yol açmaktadır. Araştırmacılar son zamanlarda prognostik belirteçler ve tedavi hedefleri olarak olası rollerini ortaya koymak için biyolojik ve moleküler hedeflere yönelmektedir. C-erbB-2 olarak da bilinen HER-2/neu onkogeni, kromozom 17q21'de lokalizedir. HER1, HER3 ve HER4 gibi epidermal büyüme faktör reseptörleri ile benzer şekilde, tirozin kinaz reseptör ailesinin bir üyesidir ve transmembran epidermal büyüme faktörü reseptörü (EGFR) ile homologdur. HER-2/neu'nun aktivasyonu, hücre proliferasyonu ve farklılaşması için gerekli olan MAPK/P13K/AKT gibi sinyal yolaklarının uyarılmasına yol açar. $\mathrm{Bu}$ nedenle neoplastik hücrelerin büyümesinde ve progresyonunda rol oynar. HER2/neu'nun aşır1 ekspesyonu akciğer, prostat, mesane, pankreas ve meme gibi birçok epitelyal malignitelerde tespit edilmiştir. Örneğin meme kanserli olguların \%2535'inde HER-2/neu aşırı ekspresyonu tespit edilmiştir. $\mathrm{Bu}$ hastaların bir anti-HER-2/neu monoklonal antikoru olan trastuzumab (Herceptin) ile tedavisinin, tümör hacmini azalttığı, kemoterapinin etkisini artırdı $\breve{1} 1$, primer ve metastatik meme kanserinde sağ kalım oranını arttırdığ gösterilmiştir. Meme kanserinde anti-HER-2/neu tedavisinin başarısı, aralarında KRK'inde yer aldığı birçok tümörde HER-2/neu ekspresyonunun araştırılmasına yol açmıştır. KRK'da ekspresyonu ile ilgili olarak \%0-\%80 arasında değişen oranların olduğu yayınlar vardır (4-8)

$\mathrm{Bu}$ çalışmanın amacı; kolorektal kanserlerde HER-2/neu onkogeni ekspresyonunu immunohistokimyasal yöntemlerle belirlemek ve aşırı ekspresyonunun; yaş, cinsiyet, lokalizasyon, patolojik evre(pT evre), histolojik derece, tümör boyutu, lenfovasküler ve perinöral invazyon varlığ cerrahi sınırların durumu, lenf nodu metastazı, uzak metastaz gibi prognostik faktörler arasındaki ilişkiyi değerlendirmektir.

\section{Gerec ve Yöntem}

Muğla Sitkı Koçman Üniversitesi İnsan Araştırmaları Etik Kurulu'ndan 24.07.2018 tarih ve 129 sayılı yazı ile izin alınmıştır. Bu çalışmaya 2013-2020 y1lları arasında Muğla Sitkı Koçman Üniversitesi Tıp Fakültesi Tıbbi Patoloji Anabilim Dalı'nda incelenen ve kolorektal karsinom tanis1 alan 111 kolorektal rezeksiyon materyali dahil edildi. Olgulara ait yaş, cinsiyet, tümör lokalizasyonu, uzak organ metastazı, yaşam süresi gibi klinik bilgiler hastanemiz otomasyon sistemindeki hastaların izlem dosyalarından elde edildi. Ayrıca tümör boyutu, lenfovasküler ve perinöral invazyon varlığı, cerrahi sınırların durumu, lenf nodlarının durumu gibi bulgular hastaların patoloji raporlarından elde edildi. Tümörlerin histolojik alt gruplara ayrılması ve patolojik evrelemesi (pT evre) Dünya Sağlık Örgütünün Sinıflandırmasına göre yapıldı.

Rutin yöntemlerle fikse edilmiş (\%10'luk tamponlanmış formalinde tespit edilmiş) ve parafin bloklara gömülmüş tümörlü doku örneklerine ait HE boyalı lamlar histolojik olarak revize edildi ve ilgili parafin bloklar arşivden alındı. İmmünohistokimya için seçilen tümörlü parafin bloklardan 3-4 mikron kalınlığında kesitler alındı ve boyama prosedürü Leica Bond-Max cihazında anti-HER2/neu antikoru (Leica) kullanılarak otomatik sistemle boyandı.

$$
\text { C-erb-B2 }
$$
immunreaktivitesinin değerlendirilmesi için daha önce bildirilmiş bir yarı kantitatif skorlama sistemi uygulandı ve membranöz boyanma dikkate alındı. Lamlar subjektif yanlılı̆̆ önlemek için iki deneyimli patoloji uzmanı tarafından birbirinden bağımsız olarak 1 şık mikroskopunda değerlendirildi ve skorland. İmmunreaktivitenin değerlendirilmesi: 0, reaktivite yok veya tümör hücrelerinin <\%10'unda membranöz boyanma; 1+, tümör hücrelerinin $>\% 10$ 'unda zayıf parsiyel membranöz boyanma; $2+$, tümör hücrelerinin $>\% 10$ 'unda hafif-orta düzeyde tam membranöz boyanma; 3+, tümör hücrelerinin $>\% 10$ 'unda şiddetli tam membranöz boyanma olarak skorlandı. HER-2/neu için, 0 ve $1+$ skorları negatif, $2+$ ve $3+$ skorları pozitif ekspresyon olarak kabul edildi (4-7).

İstatistiksel Değerlendirme: Her iki grubun klinik özellikleri SPSS ile karşılaştırıldı (Statistical Package for Social Sciences) v22.0 (SPSS Inc., Chicago, IL, USA). Yaş ve tümör boyutu gibi numerik değişkenler ortalama \pm standart şeklinde hesapland1. Histopatolojik özellikler var/yok şeklinde belirtildi. Evre ve diferansiyasyon güncel DSÖ kriterlerine göre sınıflandırıldı. Lokalizasyon ise tümör yeri şeklinde belirtildi. Kategorik değişkenler arasındaki ilişkinin değerlendirilmesinde ki kare testi kullanıldı. İstatistiksel olarak anlamlılık düzeyi $\mathrm{p}<0.05$ olarak belirlendi.

\section{Bulgular}

Çalışmaya dahil edilen 111 olgunun ortalama yaşı $65.4 \pm 11.2$ (38-95 yaş aralığı) ve 72 'si erkek (\%64.9), 39'u kadın (\%35.1) idi. Olguların demografik verileri ve tümör özellikleri Tablo 1'de özetlenmiştir.

İmmunohistokimyasal çalışmada; 26 (\%23.4) olgu reaktivite yok veya tümör hücrelerinin $<\% 10$ 'unda membranöz boyanma (skor 0), 33 (\%29.7) olgu tümör hücrelerinin $>\% 10$ 'unda zayıf parsiyel membranöz boyanma (skor 1), 30 (\%27) olgu tümör hücrelerinin >\%10'unda hafif-orta düzeyde tam membranöz boyanma (skor 2), 22 
(\%19.8) olgu tümör hücrelerinin $>\% 10$ 'unda şiddetli tam membranöz boyanma (skor 3) olarak skorlandi. Boyanma paternleri Resim 1,2,3,4'te görülmektedir [Resim 1: Skor 0 (Anti HER-2/neu x200), Resim 2: Skor 1 (Anti HER-2/neu x100), Resim 3: Skor 2 (Anti HER-2/neu x200), Resim 4: Skor 3 (Anti HER-2/neu x200)].

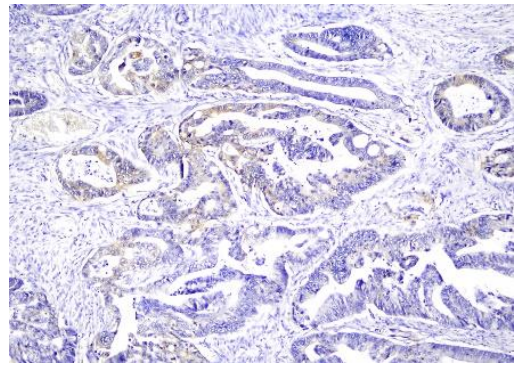

Resim 1. Skor 0 (Anti HER-2/neu x200)

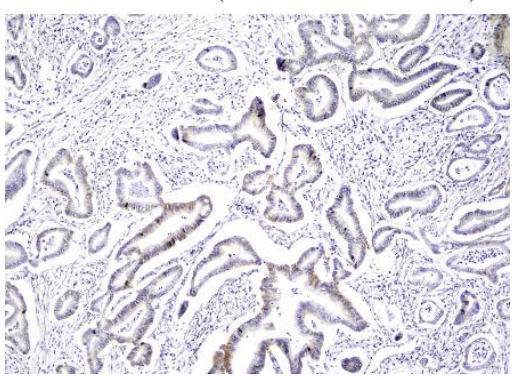

Resim 2. Skor 1 (Anti HER-2/neu x100)

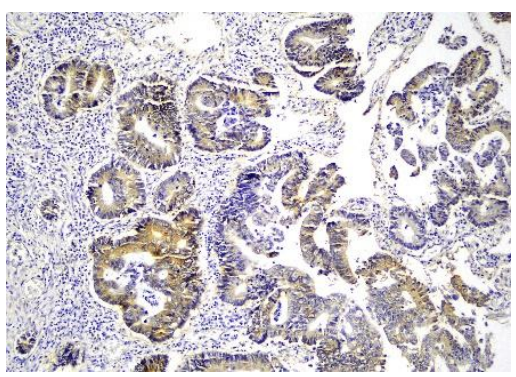

Resim 3. Skor 2 (Anti HER-2/neu x200)

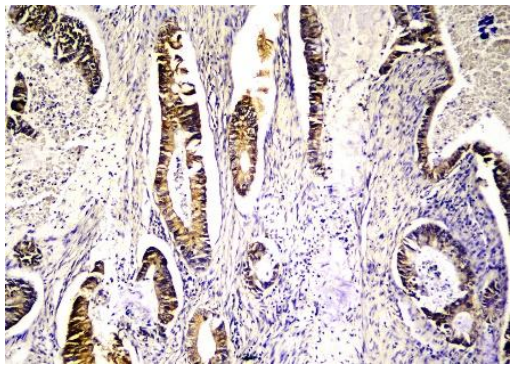

Resim 4. Skor 3 (Anti HER-2/neu x200)

HER-2/neu ekspresyonu için, 59 (\%53.15) olgu negatif (skor 0 ve 1), 52 (\%46.85) olgu pozitif (skor 2 ve 3 ) olarak kabul edildi. HER-2/neu aşır1 ekspresyonu patolojik evre, tümör diferansiasyonu, lenfovasküler invazyon, perinöral invazyon, çevre (radial) cerrahi sınır pozitifliği, lenf nodu tutulumu ve uzak metastaz varlığı ile anlamlı derecede ilişkili olduğu saptandı. Yaş, cinsiyet, tümör lokalizasyonu, distal-proksimal cerrahi sinırların durumu ve sağkalım ile korelasyon saptanmadı (Tablo 2).
Tablo 1. Olguların demografik ve klinikopatolojik özellikleri

\begin{tabular}{|c|c|c|}
\hline & $\mathbf{n}$ & $\%$ \\
\hline \multicolumn{3}{|l|}{ Yaş } \\
\hline$<60 Y$ & 35 & 31.5 \\
\hline$\geq 60 Y$ & 76 & 68.5 \\
\hline \multicolumn{3}{|l|}{ Cinsiyet } \\
\hline Erkek & 72 & 64.9 \\
\hline Kadın & 39 & 35.1 \\
\hline \multicolumn{3}{|l|}{ Lokalizasyon } \\
\hline Sağ kolon & 33 & 29.7 \\
\hline Transvers kolon & 15 & 13.5 \\
\hline Sol kolon & 7 & 6.3 \\
\hline Sigmoid-rektosigmoid & 26 & 23.4 \\
\hline Rektum & 30 & 27 \\
\hline \multicolumn{3}{|l|}{ pT Evre } \\
\hline 1 & 3 & 2.7 \\
\hline 2 & 16 & 14.4 \\
\hline 3 & 51 & 45.9 \\
\hline 4 & 41 & 36.9 \\
\hline \multicolumn{3}{|c|}{ Diferansiyasyon (Histolojik Derece) } \\
\hline İyi & 24 & 21.6 \\
\hline Orta & 77 & 69.4 \\
\hline Kötü & 10 & 9 \\
\hline \multicolumn{3}{|l|}{ Lenfovasküler invazyon } \\
\hline Yok & 52 & 46.8 \\
\hline Var & 59 & 53.2 \\
\hline \multicolumn{3}{|l|}{ Perinöral invazyon } \\
\hline Yok & 48 & 43.2 \\
\hline Var & 63 & 56.8 \\
\hline \multicolumn{3}{|l|}{ Çevre(radial) cerrahi sınır } \\
\hline Negatif & 84 & 75.7 \\
\hline Pozitif & 27 & 24.3 \\
\hline \multicolumn{3}{|l|}{ Proksimal cerrahi sınır } \\
\hline Negatif & 110 & 99.1 \\
\hline Pozitif & 1 & 0.9 \\
\hline \multicolumn{3}{|l|}{ Distal cerrahi sınır } \\
\hline Negatif & 111 & 100 \\
\hline Pozitif & 0 & 0 \\
\hline \multicolumn{3}{|l|}{ Lenf nodu metastazı } \\
\hline Yok & 54 & 48.6 \\
\hline Var & 57 & 51.4 \\
\hline \multicolumn{3}{|l|}{ Uzak metastaz } \\
\hline Yok & 85 & 76.6 \\
\hline Var & 26 & 24.4 \\
\hline \multicolumn{3}{|l|}{ Sağkalım } \\
\hline Ex & 29 & 26.1 \\
\hline Yaşıyor & 82 & 73.9 \\
\hline
\end{tabular}

\section{Tartışma}

Tirozin kinaz aktivitesi ile bir transmembran proteini kodlayan gen olan HER-2/neu, epidermal büyüme faktörü (EGFR) ile biyolojik olarak yakından ilişkili bir protoonkogendir. Gen amplifikasyonu, protein ekspresyon seviyeleri ile oldukça korele olduğundan, HER-2/neu reseptör proteinlerini belirlemek için immunohistokimyasal yöntemler tercih edilebilir. HER-2/neu amplifikasyonunu saptamak için floresan in situ hibridizasyon (FISH) ve kromojenik in situ hibridizasyon (CISH) analizleri gibi in situ DNA hibridizasyon yöntemleri de kullanılır (6). HER2/neu' nun aşırı ekspresyonu meme, mide, akciğer ve mesane kanserleri gibi pek çok kanserde tanımlanmıştır(5,9). Pozitifliği kötü prognozla ilişkilidir. Kolorektal kanserler için prognostik biomarker olarak kullanılabileceği yönünde çalışmalar giderek ön plana çıkmaktadır $(1,5)$. 
Tablo 2. HER-2/neu immunreaktivitesinin demografik ve klinikopatolojik verilerle karşılaştırılması

\begin{tabular}{|c|c|c|c|}
\hline $\begin{array}{l}\text { HER-2/neu } \\
\text { immunreaktivitesi }\end{array}$ & $\begin{array}{c}\text { Negatif } \\
\mathbf{n}=59\end{array}$ & $\begin{array}{c}\text { Pozitif } \\
\mathrm{n}=52\end{array}$ & $\mathbf{p}$ \\
\hline \multicolumn{4}{|l|}{ Yaş } \\
\hline$<60 Y$ & 21 & 14 & \\
\hline$\geq 60 Y$ & 38 & 38 & 0.327 \\
\hline \multicolumn{4}{|l|}{ Cinsiyet } \\
\hline Erkek & 42 & 30 & \\
\hline Kadın & 17 & 22 & 0.198 \\
\hline \multicolumn{4}{|l|}{ Lokalizasyon } \\
\hline Sağ kolon & 14 & 19 & \\
\hline Transvers kolon & 10 & 5 & \\
\hline Sol kolon & 4 & 3 & \\
\hline Sigmoid-rektosigmoid & 13 & 13 & \\
\hline Rektum & 18 & 12 & 0.515 \\
\hline \multicolumn{4}{|l|}{ pT Evre } \\
\hline 1 & 2 & 1 & \\
\hline 2 & 14 & 2 & \\
\hline 3 & 29 & 22 & \\
\hline 4 & 14 & 27 & 0.002 \\
\hline \multicolumn{4}{|l|}{$\begin{array}{l}\text { Diferansiyasyon } \\
\text { (Histolojik Derece) }\end{array}$} \\
\hline İyi & 15 & 9 & \\
\hline Orta & 43 & 34 & \\
\hline Kötü & 1 & 9 & 0.014 \\
\hline \multicolumn{4}{|l|}{ Lenfovasküler invazyon } \\
\hline Yok & 47 & 5 & \\
\hline Var & 12 & 47 & $<0.001$ \\
\hline \multicolumn{4}{|l|}{ Perinöral invazyon } \\
\hline Yok & 36 & 12 & \\
\hline Var & 23 & 40 & $<0.001$ \\
\hline \multicolumn{4}{|l|}{ Çevre(radial) cerrahi sınır } \\
\hline Negatif & 53 & 31 & \\
\hline Pozitif & 6 & 21 & $<0.001$ \\
\hline \multicolumn{4}{|l|}{ Lenf nodu metastazı } \\
\hline Yok & 45 & 9 & \\
\hline Var & 14 & 43 & $<0.001$ \\
\hline \multicolumn{4}{|l|}{ Uzak metastaz } \\
\hline Yok & 56 & 29 & \\
\hline Var & 3 & 23 & $<0.001$ \\
\hline \multicolumn{4}{|l|}{ Sağkalım } \\
\hline Ex & 11 & 18 & \\
\hline Yaşıyor & 48 & 34 & 0.090 \\
\hline
\end{tabular}

Li ve arkadaşlarının 317 KRK olgusunda yaptıkları immunohistokimyasal çalışmada HER2/neu'nun ekspresyonu ile tümör çapı ve uzak metastaz varlığı ile korelasyon bulunmuşken, sağkalım arasında korelasyon saptanmamıştır (4). Albayrak ve arkadaşlarının 50 hastada yaptıkları çalışmada HER-2/neu ekspresyonu histolojik tip ve lenfositik infiltrasyon ile korele iken, tümör boyutu, tümör büyüme paterni, tümör lokalizasyonu, evre, lenf nodu tutulumu, lenfatik invazyon ile korelasyon bulunmamıştır(5). Farzand ve arkadaşlarının mide (11), ince barsak(8) ve kolorektal (31) karsinomlu toplam 50 olgudan oluşan çalışmasında tümör derecesi ile HER-2/neu aşırı ekspresyonu arasında anlamlı ilişki bulunmuştur (8).Yun-Feng Yao ve arkadaşları 106 KRK olgusunda HER-2/neu ekspresyonu ile yaş, cinsiyet, tümör regresyon derecesi, TNM evresi, lenfovasküler invazyon varlığı ve tümör diferansiasyonu arasinda korelasyon bulunmazken, uzak metastaz varlığı ile anlamlı ilişki saptamışlardır (9). Benzer şekilde, Feng-Juan Gao ve arkadaşları da uzak metastaz varlığ 1 ile HER-2/neu aşırı ekspresyonunun korele olduğunu rapor etmişlerdir (10). Sun ve arkadaşları, 4942 KRK'lu, 521 sağlıklı kontrol grubunu içeren 30 çalışmanın meta-analizini yaptıkları araştırmada, HER-2/neu ekspresyonunun KRK'lu olgularda kontrol grubuna göre daha şiddetli olduğu ve lenf nodu metastazı olan KRK olgularında metastaz olmayanlara göre HER-2/neu ekspresyonunun anlamlı olarak daha yüksek olduğu tespitini yapmişlar, HER-2/neu ekspresyonu ile klinikopatolojik özellikler arasında net bir korelasyon olduğunu ve bu nedenle HER-2/neu'nun KRK tanisinda ve prognozunu tahmin etmede potansiyel bir biyolojik belirteç olabileceğini belirtmişlerdir (15). Li ve arkadaşları ise yaptıkları çalışmada over metastazı olan KRK olgularında primer tümörde HER-2/neu ekspresyonunun, metastaz olmayan olgulara göre anlamlı olarak daha yüksek olduğunu ve HER-2/neu pozitif over metastazlı KRK hastalarında sağkalım süresinin HER-2/neu negatif olanlara göre daha kısa olduğunu tespit etmişlerdir (16).

Öte yandan, Drecoll ve arkadaşları HER-2/neu ekspresyonu ile tümör derinliği, tümör lokalizasyonu, diferansiasyon, lenf nodu tutulumu ve uzak metastaz varlığı arasında anlamlı ilişki bulamamışlardır (11). Benzer şekilde Sayadnejad ve arkadaşları 50 olguluk çalışmalarında, yaş, tümör boyutu, cinsiyet, lokasyon, derece ve evre ile HER2/neu ekspresyonu arasında anlamlı ilişki saptamamışlardır(13). Priyanka ve arkadaşları ise çalışmalarına dahil ettikleri 25 kolorektal kanserli olgunun tamaminda HER-2/neu ekspresyonunu negatif saptamışlardır (14). Madani ve arkadaşları ise 182 olguluk seride HER-2/neu ekspresyonu ile tümör diferansiasyonu arasında anlamlı ilişki tespit etmişlerdir, ancak diğer çalışmalardan farklı olarak iyi diferansiye tümörlerde ekspresyon şiddetinin arttığını rapor etmişlerdir (12).

Sonuç olarak günümüze kadar yapılan birçok çalışmada HER-2/neu ekspresyonunun prognoz üzerine etkisi ve klinikopatolojik parametrelerle korelasyonu hakkında tartışmalar devam etmekte olup, sonuçlar arasında farklılıklar olmaktadır. Bizim çalışmamızda HER-2/neu aşırı ekspresyonu ile patolojik evre, lenfovasküler invazyon, perinöral invazyon, çevre (radial) cerrahi sınır pozitifliği, lenf nodu tutulumu ve uzak metastaz varlığı gibi klinikopatolojik ve kötü prognostik parametrelerle istatiksel olarak anlamlı ilişki tespit edilmiş olup, KRK'lu hastalarda HER-2/neu ekspresyonu tespitinin, hastalığın prognozunu öngörmede ve tedavi protokollerinin belirlenmesinde yol gösterici olabileceğini düşünmekteyiz.

Etik Kurul Onayı: Muğla Sitkı Koçman Üniversitesi İnsan Araştırmaları Etik Kurulu'ndan 24.07.2018 tarih ve 129 sayılı yazı ile izin alınmıştır. 


\section{Kaynaklar}

1. WHO Classification of Tumours Editorial Board. Digestive system tumours, 5th Edition. 158-191. Lyon(France): International Agency for Research on Cancer, 2019.

2. Rawla P, Sunkara T, Barsouk A. Epidemiology of colorectal cancer: incidence, mortality, survival and risk factors. Gastroenterol Rev. 2019;14(2):89-103.

3. Rosai J.Rosai and Ackerman's Surgical Pathology. 10th ed. St Louis, MO:St Louis Mosby, 2011:731-803.

4. Li Q, Wang D, Li J and Chen P. Clinicopathological and prognostik significance of HER-2/neu and VEGF expression in colon carcinomas. BMC Cancer. 2011;11:277.

5. Albayrak A, Gürsan N, Gündoğdu C. Kolorektal kanserlerde c-erbB-2 ve p53 ekspresyonunun prognostik önemi. JCEI. 2014;5(1):80-5.

6. Yildırım S, Dandin O, Durmus $M$ ve ark. C-erbB2(Her2/neu) Expression Rate And its Association with Clinicopathologic Parameters in Gastric Cancer. UHOD. 2012;22(3):156-62.

7. Valorta E, Martino C, Sartore-Bianchi A ve ark. Assessment of a HER2 scoring system for colorectal cancer: results from a validation study. Modern Pathol. 2015; 28: 1481-91

8. Farzand S, Siddique T, Saba K, Bukhari MH. Frequency of HER2/neu overexpression in adenocarcinoma of the gastrointestinal system. World J Gastroenterol. 2014;20(19):5889-96.
9. Yao YF, Du CZ, Chen N, Chen P, Gu J. Expression of HER-2 in rectal cancers Treated With preoperative Raditherapy:a potential Biomarker Predictive of Metastasis. Dis Colon Rectum. 2014;57:602-7.

10. Gao FJ, Chen JY, Wu HY ve ark. Lgr5 over-expression is positively related to the tumor progression and HER2 expression in stage pTNM IV colorectal cancer. Int J Clin Exp Pathol. 2014;7(4):1572-9.

11. Drecoll E, Nitsche U, Bauer K ve ark. Expression analysis of heat shock protein 90(HSP90) and Her2 in colon carcinoma. Int J Colorectal Dis. 2014;29:663-71.

12. Madani SH, Sadeghi E, Rezaee A ve ark. Survey of HER2neu Expression in Colonic Adenocarcinoma in the West of Iran. Asian Pac J Cancer Prev. 2015; 16(17):7671-4.

13. Sayadnejad N, Firouzjahi A, Shafaee $S$ ve ark. Immunohistochemical Study of HER2/neu Expression in colorectal Cancer and its Relation to other Clinicopathological Criteria and Prognostic Factors. Int J Cancer Manag. 2017;10(5):e5700.

14. Priyanka G, Joseph LD, Barathi G, Kumbhat M. HER $2 /$ neu as a theranostic marker in colorectal carcinoma and its relationship with histopathological correlates-A pilot study. Indian J Pathol Oncol. 2017;4(3):446-9.

15. Sun SJ, Lin Q, Sun Q et al. High HER-2 protein levels correlate with clinicopathological features in colorectal cancer. J Can Res Ther. 2016;12(1):323-33.

16. Li JL, Lin SH, Chen HQ et al. Clinical significance of HER2 and EGFR expression in colorectal cancer patients with ovarian metastasis. BMC Clinical Pathol. 2019;19:3. 